\title{
Site Characterization Using Integrated Imaging Analysis Methods on Satellite Data of the Islamabad, Pakistan, Region
}

\author{
by Alan Yong, Susan E. Hough, Michael J. Abrams, Helen M. Cox, \\ Christopher J. Wills, and Gerry W. Simila
}

\begin{abstract}
We develop an integrated digital imaging analysis approach to produce a first-approximation site characterization map for Islamabad, Pakistan, based on remote-sensing data. We apply both pixel-based and object-oriented digital imaging analysis methods to characterize detailed $(1: 50,000)$ geomorphology and geology from Advanced Spaceborne Thermal Emission and Reflection Radiometer (ASTER) satellite imagery. We use stereo-correlated relative digital elevation models (rDEMs) derived from ASTER data, as well as spectra in the visible near-infrared (VNIR) to thermal infrared (TIR) domains. The resulting geomorphic units in the study area are classified as mountain (including the Margala Hills and the Khairi Murat Ridge), piedmont, and basin terrain units. The local geologic units are classified as limestone in the Margala Hills and the Khairi Murat Ridge and sandstone rock types for the piedmonts and basins. Shear-wave velocities for these units are assigned in ranges based on established correlations in California. These ranges include $V_{s} 30$-values to be greater than $500 \mathrm{~m} / \mathrm{sec}$ for mountain units, $200-600 \mathrm{~m} / \mathrm{sec}$ for piedmont units, and less than $300 \mathrm{~m} / \mathrm{sec}$ for basin units. While the resulting map provides the basis for incorporating site response in an assessment of seismic hazard for Islamabad, it also demonstrates the potential use of remote-sensing data for site characterization in regions where only limited conventional mapping has been done.
\end{abstract}

\section{Introduction}

Site characterization is a critical part of seismic hazard assessments because local geology has long been known to have a substantial effect on earthquake ground motions (Wood, 1908; Reid, 1910; Aki, 1988; Faccioli, 1991; Boore and Joyner, 1997; Kawase, 2003). The physical properties of the rock are probably the most obvious factors that control the seismic velocity (impedance) and thus amplify (or deamplify) seismic energy. To relate rock types to expected amplification factors, one must estimate shear-wave velocity, a proxy for impedance, for each lithologic unit (Borcherdt, 1970; Park and Elrick, 1998). Classifications of site conditions are made on the basis of $V_{s} 30$-values, the average seismic shear-wave velocity through the upper $30 \mathrm{~m}$ of the subsurface (Borcherdt, 1994; International Conference of Building Officials, 1997), and are typically added as a correction term to ground-motion models or attenuation relations (e.g., Abrahamson and Silva, 1997; Boore and Joyner, 1997; Campbell, 1997; Sadigh et al., 1997).

In some seismically active regions, considerable effort has been made to develop site characterization maps. For example, Wills et al. (2000) and Wills and Clahan (2006) presented 1:250, 000 scale site classification maps of California. While these maps allow for site characterization to be in- cluded in hazard mapping at a coarse scale (e.g., Field et al., 2005), Wills et al. (2000) tested their results and found that $26 \%$ of the independent site measurements do not fall within the range of their expected categories. A recent study by Tinsley et al. (2004) found an even higher misclassification rate for the Southern California Seismic Network (SCSN) station sites. SCSN sites might be especially prone to misclassification by a coarse map; for example, a station might be specifically sited on an isolated hard rock outcrop in an area that is broadly characterized as a sedimentary valley. In any case, even in a region as well studied as California, effective microzonation will require more precise site characterization than can be achieved with conventional geological mapping methods alone.

In many regions around the world, site response is expected to be an important component of seismic hazard analysis, but site characterization maps are often crude or unavailable. For these regions, it is necessary to develop first-approximation maps. In this study, we develop and apply digital imaging analysis techniques on satellite imagery of the region surrounding Islamabad, the capital of Pakistan (Fig. 1), to test the capabilities of high resolution remotesensing technology for site characterization. 


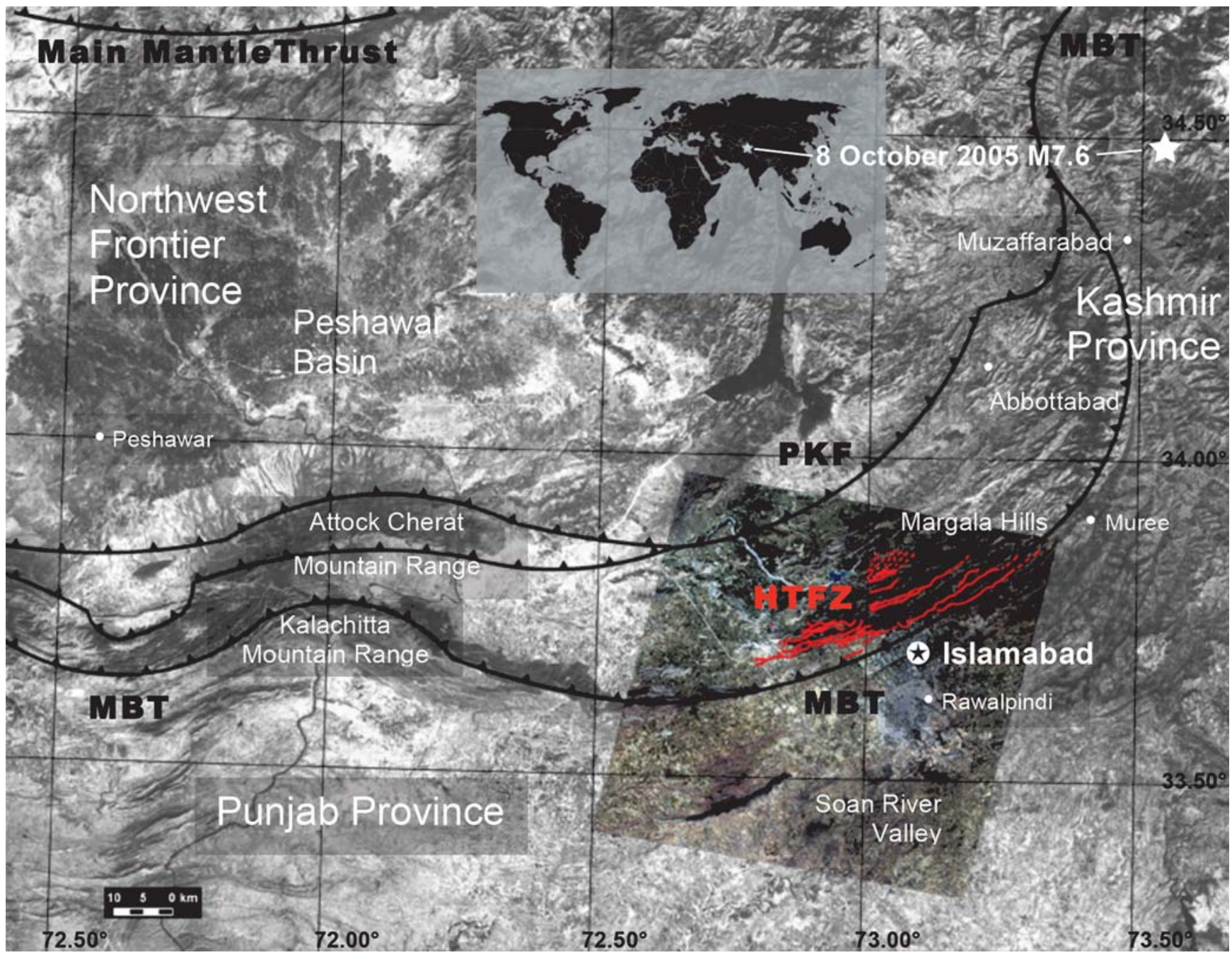

Figure 1. Map of the northern Pakistan region (source: EarthSat NaturalVue Global Landsat Mosaic). Our study area is denoted by the footprint of the true-color image. Additional information includes selected cities and physiography, the epicenter of the $M 7.6 \mathrm{Muzaffarrabad}$ earthquake, and our generalization of the selected thrust fault systems in the region based on Coward et al. (1987), Baker et al. (1988), Williams et al. (1999), and MonaLisa et al. (2004, 2007). Abbreviations: HTFZ denotes the Hazara thrust fault zone, MBT denotes the main boundary thrust, and PKF denotes the Panjal-Khairabad fault.

The terrain of this region consists of plains and mountains with a general physiography that trends east-northeast (Williams et al., 1999). The city of Islamabad is adjacent to a mountainous terrain known as the Margala Hills, part of the lower and outer Himalaya Range consisting of a series of ridges with altitudes reaching approximately $1600 \mathrm{~m}$ near Islamabad. The Margala Hills are an intensely deformed tectonic belt that represents the uplift of the Peshawar Basin that is part of the active Himalayan foreland where fold and thrust belts form the collision zone between the Indian and Eurasian plates (Coward et al., 1987; Baker et al., 1988; Bender and Raza, 1995; Pivnik and Wells, 1996). South of the Margala Hills is a southward sloping piedmont bench (Williams et al., 1999) where the Islamabad and Rawalpindi urban developments are situated. Farther south, the Soan River Valley extends outward to the plains of the Potwar Plateau beyond the study area (Baker et al., 1988).
The lithology of the Islamabad and Rawalpindi area has been broadly classified by Williams et al. (1999) as follows: (1) the northern mountainous Margala Hills consist of folded and thrust limestones and shales (Pivnik and Wells, 1996; Munir and Butt, 2007); (2) the piedmont bench consists of truncated and folded sandstones and shales, in addition to buried and exposed ridges of sandstones and shales west of Rawalpindi; and (3) the asymmetric syncline of the Soan River Valley consists of beds of fluvial sandstone, mudstone, and conglomerate. As a depositional system, the piedmont accumulates silt and alluvial gravel from the Margala Hills, which eventually spreads and fills the wide plains of low relief (Williams et al., 1999). Because of the dry climate, welldeveloped soils are scarce in the Islamabad area (Williams et al., 1999).

As discussed by MonaLisa et al. (2004, 2007), seismic hazards in Islamabad and Rawalpindi are largely associated 
with several faults in proximity to the region, including: the Main Boundary Thrust (MBT) and the Margala, Hazara, Panjal, Jhelum, Manshera, and Muree faults. The closest fault systems are (1) the MBT (Fig. 1), which is approximately $270 \mathrm{~km}$ long and extends along the Himalayan Front, passing about $1 \mathrm{~km}$ south of the Margala Hills, (2) the PanjalKhairabad fault (PKF) (Fig. 1), which passes north of the Margala Hills at approximately $26 \mathrm{~km}$, and (3) the Hazara thrust fault system or zone (HTFZ) (Fig. 1), which has three branches in the Margala Hills with the nearest trace approximately $15 \mathrm{~km}$ from Islamabad (Coward et al., 1987; Baker et al., 1988; MonaLisa et al., 2004, 2007).

In addition to the hazards posed by local faults, more distant faults also contribute an important component of hazard in the Islamabad region. This effect of site condition was demonstrated by the 8 October $2005 M 7.6$ earthquake near Muzaffarabad in the Kashmir region (Fig. 1). The earthquake, which struck approximately $100 \mathrm{~km}$ northeast of Islamabad, caused about 86,000 fatalities, 100,000 injuries, and heavy structural damage (National Earthquake Information Center (NEIC), 2005). Most of the damage was concentrated in the mountainous epicentral region; however, significant damage also occurred on sediment sites in Islamabad and the nearby city of Rawalpindi (NEIC, 2005). In general, seismic hazard in the Islamabad region is thought to be lower than along the active plate boundary faults in the mountainous region north and northwest of the city (e.g., Giardini, 1999), but by virtue of sediment-induced amplification, relatively distant earthquakes will also contribute a significant component to hazard.

The 2005 Kashmir earthquake provided the impetus for the government of Pakistan to improve seismic hazard characterization. This in turn provided the impetus for us to consider the Islamabad region as a test case for our approach.

To explore the potential of newly available remotesensing imagery to improve existing site characterization maps and to develop first-approximation maps in regions where they are unavailable, we develop and apply automated digital imaging analysis methods by integrating pixel-based and object-oriented methods on Advanced Spaceborne Thermal Emission and Reflection Radiometer (ASTER) satellite imagery to characterize seismic site effects based on the interpretations of geomorphologic and geologic features. Although the methods employed in this study have already been applied in other disciplines (e.g., Yan, 2003; Agarkov et al., 2005; Argialas and Tzotsos, 2006), only limited approaches have previously been attempted (e.g., Romero and Rix, 2001; Wald and Allen, 2007) for application in seismic hazards analysis. In this study, we explore the potential of remote-sensing data to determine site characterization based on geomorphology as well as geology at a finer level of detail than has previously been possible.

\section{Remote-Sensing Data}

Modern remote-sensing systems are commonly designed to acquire data for specific purposes. The ASTER instrument was designed specifically for geologic investigations (Abrams and Hook, 1995). ASTER is one of the four National Aeronautics and Space Administration (NASA) Earth Observation System (EOS) instruments on board the multiplatform satellite Terra. It has a sun-synchronous orbit at an altitude of $750 \mathrm{~km}$ and returns to the same orbit every 16 days. The ASTER detection and recording system utilizes a set of four optical telescopes that collect spectra in three separate recording subsystems (Abrams et al., 2002) (Table 1). The visible near-infrared (VNIR) system records four discrete bandpasses (channels 1,2, 3N, and 3B) that are collected from two separate telescopes: a nadir-viewing telescope that records channels 1,2 , and $3 \mathrm{~N}$ and a backwardviewing telescope that records channel 3B. Both telescopes can be rotated $( \pm 24)$ as a unit and have spatial resolutions of $15 \mathrm{~m}$. The shortwave infrared (SWIR) system records six discrete bandpasses (channels 4-9) that are collected from a fixed viewing telescope that uses an adjustable $\left( \pm 8.54^{\circ}\right.$ from nadir) scanning mirror for rotation and has a spatial resolution of $30 \mathrm{~m}$. Also using an adjustable scanning mirror with the same rotational range, the thermal infrared (TIR) channel system records five discrete bands (channels 10-14) and has a spatial resolution of $90 \mathrm{~m}$.

Two sets of ASTER imagery of the Islamabad region were recorded on 3 November 2005 and were acquired from the EOS Data Gateway (EDG) (see Data and Resources section). The first set is the ASTER Level-1B (AST_L1B) product consisting of 14 discrete spectral bands ranging from the VNIR-TIR $(0.52-11.65 \mu \mathrm{m})$ region (Table 1$)$. The second set is the ASTER Level-3 (AST14DEM) relative digital elevation model (rDEM) product derived from stereo correlation of spectral bands in the VNIR region $(0.78-0.86 \mu \mathrm{m})$ (Table 1). Each level of product has characteristics based on

Table 1

Characteristics of the Three ASTER Sensor Subsystems (Abrams et al., 2002)

\begin{tabular}{cccc}
\hline Subsystem & Band Number & Spectral Range $(\mu \mathrm{m})$ & Spatial Resolution $(\mathrm{m})$ \\
\hline VNIR & 1 & $0.52-0.60$ & 15 \\
& 2 & $0.63-0.69$ & \\
& $3 \mathrm{~N}$ & $0.78-0.86$ & \\
SWIR & $3 \mathrm{~B}$ & $0.78-0.86$ & 30 \\
& 4 & $1.60-1.70$ & \\
& 5 & $2.145-2.185$ & \\
& 6 & $2.185-2.225$ & \\
& 7 & $2.235-2.285$ & \\
TIR & 8 & $2.295-2.365$ & \\
& 9 & $2.360-2.430$ & \\
& 10 & $8.123-8.475$ & \\
& 11 & $8.475-8.825$ & \\
& 12 & $8.925-9.275$ & \\
& 13 & $10.25-10.95$ & \\
& 14 & $10.95-11.65$ & \\
\hline
\end{tabular}


different parameterizations, such that the data products represent the level of processing applied to the Level-1A (AST_L1A) data, which were reconstructed from the raw digital counts (Level-0) as recorded by the ASTER subsystems (Abrams et al., 2002).

The AST_L1B data are essentially a resampled data product with correction coefficients applied to the Level1A raw data (Yamaguchi et al., 1998; Abrams et al., 2002). With AST_L1A data, geometric correction and radiometric calibration coefficients are appended but not applied, so critical factors, such as parallax caused by the offset in detector alignment in the along-track direction and the inter- and intra- telescope registrations, are not accounted for (Abrams et al., 2002). The AST_L1B data are applied with the geometric and radiometric corrections. Atmospheric corrections are applied to Level-2 products (e.g., AST_06V or decorrelation stretch-VNIR data), but not to Level-1, so the AST_L1B data used in this study include possible contributions from aerosols. For the Islamabad region, the removal of atmospheric effects is not necessary because the climate is arid, so these effects are minimal at worst.

The AST14DEM datum is a Level-3 image product generated using spectra $(0.78-0.86 \mu \mathrm{m})$ recorded from the nadir-viewing $(3 \mathrm{~N})$ and backward-viewing (3B) sensors. The Level-3 data are based on an input spatial resolution of $15 \mathrm{~m}$ and an output spatial resolution of $30 \mathrm{~m}$ (Abrams et al., 2002). The resultant digital elevation model (DEM) is based on an automated stereoscopic correlation method-a standard procedure for generating DEMs from digital stereo images (Hirano et al., 2003). The stereo pair has a base-toheight ratio of 0.6 and an intersection angle of approximately $27.6^{\circ}$ (Fig. 2), which is close to ideal for a variety of terrain conditions (Hirano et al., 2003). As opposed to other modes (e.g., cross track) of data acquisition, the along-track mode (Fig. 2) of the ASTER system produces an approximately one-minute lag time between the acquisition of the nadir

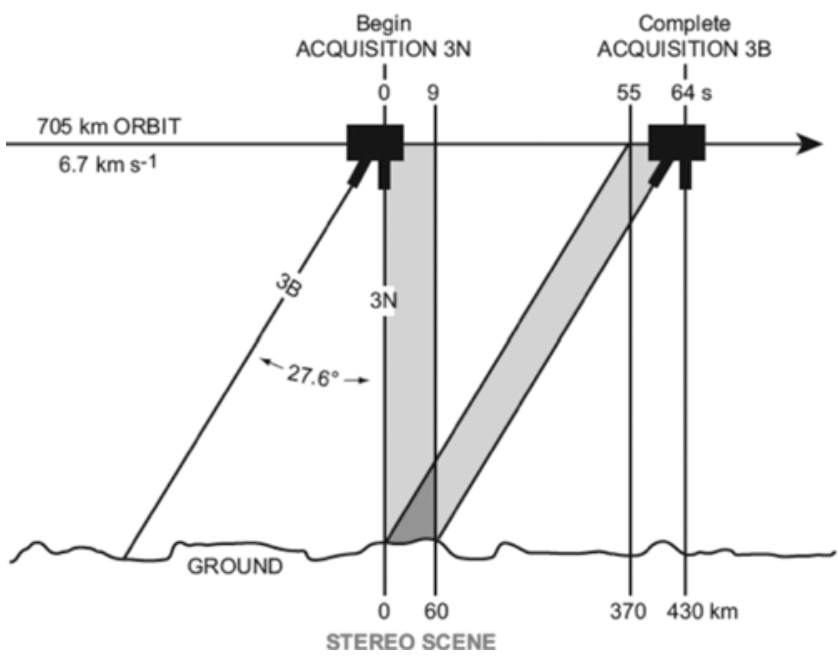

Figure 2. Geometry of the along-track recording mode for the ASTER VNIR nadir (3N) and backward (3B) viewing sensors (Kääb et al., 2002). and backward images such that images forming the stereo pairs acquire data in very similar environmental conditions, resulting in very consistent image quality (Hirano et al., 2003). In addition, the AST14DEM product is a relative DEM (rDEM), such that no ground control points (GCPs) are used to tie in correlated features on the surface; instead of GCPs, an ephemeris on board the satellite is used.

The scene dimensions for the AST_L1B and AST14DEM imagery vary in spatial and spectral resolutions (Table 1). The coverage (Fig. 3) of the AST14DEM footprint is slightly smaller than that of the AST_L1B scenes. This is caused by the use of moving windows to calculate the stereo correlation between the imagery captured by the $3 \mathrm{~N}$ and $3 \mathrm{~B}$ stereo pairs. Thus, we define our study area by the nominal extent of the AST14DEM footprint, covering an approximate $60 \times 60 \mathrm{~km}$ swath (Fig. 3).

\section{Digital Analysis Methods}

Our integrated analysis involves performing five sequential steps on the ASTER imagery. First, we employ digital imaging analysis of the rDEM to identify breaks in the spatial changes in elevation values (slope) and to assign terrain units as classes (mountains, piedmonts, and basins). Second, we digitally discriminate the lithology using spectral features (Kahle and Rowan, 1980; Abrams and Hook, 1995; Yong, 2007) found in the ASTER bands (VNIR-TIR). Third, we compare the spatial distribution of the lithology and its correlation with the preassigned terrain units to verify that the expected physical properties match the terrain unit. In the fourth step, we assign ranges of shear-wave velocity based on Wills and Silva (1998). In this step, we infer the physical properties affecting the impedance of material from a combination of terrain classes and spectral-based lithologic discriminations of the terrain units and the associated lithology. Finally, in the fifth step, we verify the identified lithology with independent geological investigations.

Digital imaging analysis methods are used for extracting information from the pixels within an image. We use two different approaches: object-oriented and pixel-based digital imaging analysis. Each of these approaches has a specific capability to effectively perform a particular type of analysis and data processing task.

Fundamentally, each method is concerned with the preassigned value of the pixel and the position of the pixel in relation to others. These pixels are usually assigned values in the form of digital numbers (DNs) representative of the raw data (e.g., radiance) (Abrams et al., 2002). It is possible to work on imagery with pixels that are based on radiance values, but for this study only pixels based on DNs are considered. The differences in the value of the DNs for each individual pixel are used to explore the various unique features (e.g., absorption bands) of the spectra to extract information about the properties of the object. Depending on the spatial resolution of the image, there are instances where the feature space of an object is the size of a single image pixel; in most 


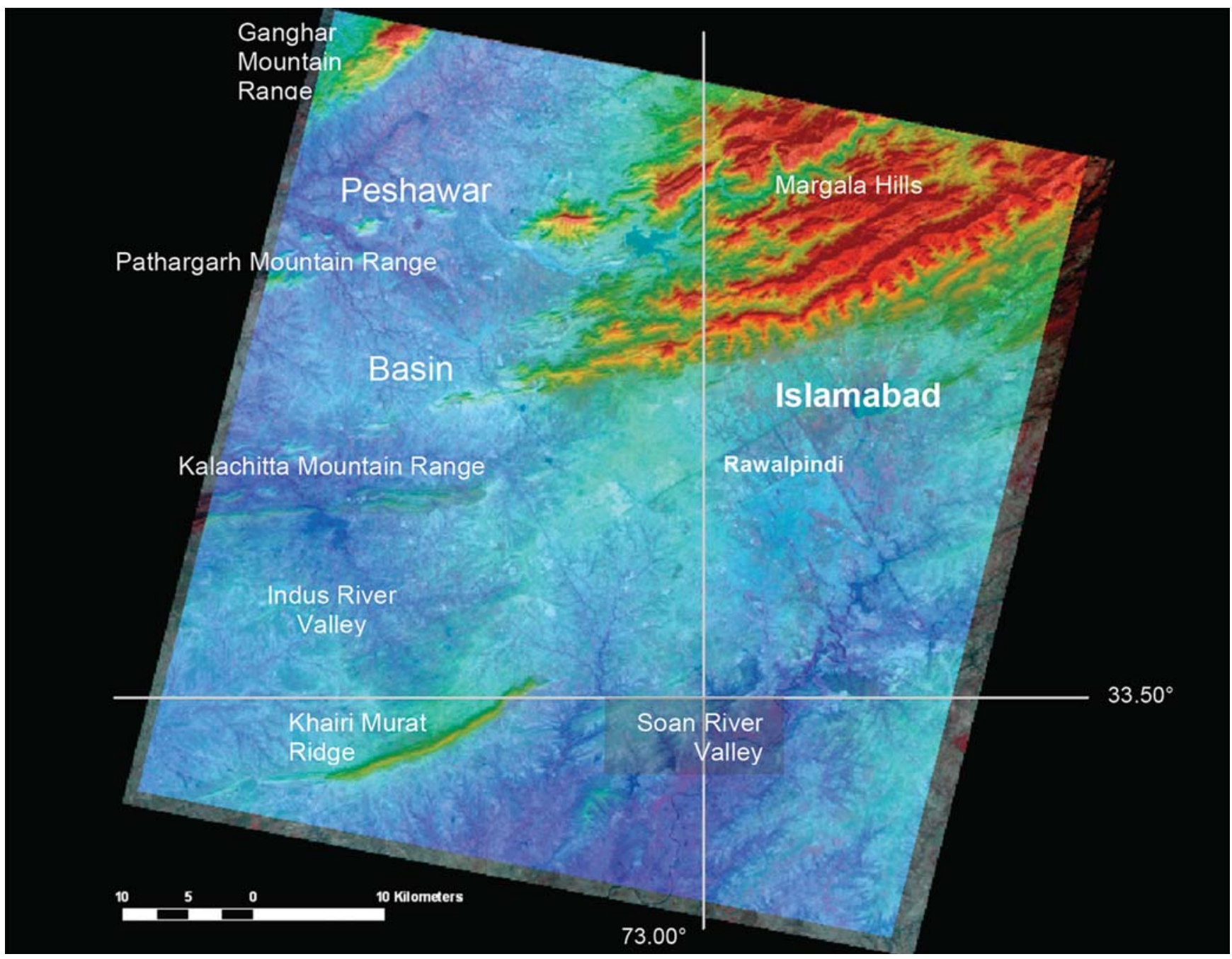

Figure 3. Compilation map of our Islamabad study area. The top image layer (intense color coding) is the relative DEM (AST14DEM) and the bottom image layer (muted color) is a VNIR composite (AST_L1B) (Fig. 5).

instances, an object comprises multiple contiguous pixels positioned collectively in its feature space.

To analyze groups of image pixels and the distribution of the collective groups of pixels for classification purposes, we use object-oriented analysis on the $30 \mathrm{~m}$ spatial resolution ASTER DEM imagery.

To analyze and visualize the value of the individual image pixels for the extraction of information about the properties of objects, this study applies the pixel-based paradigm on the multispectral resolution ASTER imagery. In this method, image-processing functions are applied to each pixel for the analysis of their individual DN to aid the interpretation of electromagnetic (EM) properties at multispectral resolutions. Furthermore, visualization capabilities can be enhanced for image pixels that have low contrast but rich information through algorithmic (mathematical) transformations. Other pixel-based transformations include the preprocessing of data for geometry-related corrections, rectification of corrupted data, and data format conversions.

\section{Relative DEM (Object-Oriented) Analysis}

To automatically identify the landforms that affect site conditions, we first translate the features into terrain units. Terrain features can be described and categorized into simple topographic relief elements or units by parameterizing DEMs (Bolongaro-Crevenna et al., 2005). Using geomorphometric parameters (slope, aspect, azimuth, concavity/convexity, etc.) to class elemental terrain features into units (mountains, piedmonts, and basins) where such features are already known makes it possible to reapply the same parameters to other regions where similar geomorphology exists. For example, using only relative slope gradients as a geomorphometric parameter, Yong et al. (2008) demonstrated that the same parameters used for Pakistan are applicable for a firstapproximation of geomorphology in other regions that have distinctively different depositional environments, such as Turkey and Mozambique. Geomorphometry also offers a variety of additional approaches for defining terrain units, such as the classification of terrain feature parameters, filter- 
ing techniques, cluster analysis, and multivariate statistics (Pike, 2002; Bolongaro-Crevenna et al., 2005).

For this study, we consider a single geomorphometric parameter, a slope factor, because the goal is a firstapproximation approach to characterize terrain features for describing seismic site conditions. Practically, for local geologic site characterization, the terrain's topographic relief is an adequate proxy to infer the physical properties that affect the impedance of the site. The use of topographic relief as a proxy for determining site conditions $\left(V_{s} 30\right)$ was recently explored by Wald and Allen (2007), who use the approach for global scale assessments that can be included in ShakeMap ground-motion models (Allen and Wald, 2007). But to verify that the topographic factor used actually reflects the expected impedance at the site, local geology must be considered. This can be performed through the spectral identification of lithology through the pixel-based spectral analysis method described in the following Spectral (Pixel-Based) Imaging/Analysis section.

We use the Definiens Professional (eCognition) software to systematically classify groups of contiguous pixels, the so-called image objects. For high $(15 \mathrm{~m})$ spatial resolution data such as the ASTER imagery, mesoscale terrain units are invariably represented by multiple contiguous pixels that are clustered collectively in a shape of finite spatial extent. To effectively classify image objects represented by multiple pixels in the image space or domain, shape, texture, color, context, and other morphological characteristics must be considered. Once the image objects in the image space are analyzed, parameterized, extracted, and segmented, they are then referred to as object primitives (Fig. 4a).

Of the three types of segmentation algorithms defined in eCognition, we chose the multiresolution segmentation algorithm because of its robustness and flexibility. It takes into account important contextual information such as: the allowable degree of heterogeneity, the importance of color, the importance of shape, the importance of compactness, and the importance of smoothness (Definiens, 2006). Based on these parameters, hierarchical levels of object primitives are created (Fig. 4) (Definiens, 2006). Through the pairwise clustering of pixels (Fig. 4b), followed by a bottom-up region-merging technique (Fig. 4b), the segmentation process takes advantage of the resultant hierarchical network of object primitives that is cognizant of its neighbor objects (Fig. 4c), its subobjects (Fig. 4c), and its superobjects (Fig. 4c), creating contextual information (based on parentchild relations) on multiple scales (Definiens, 2006).

To extract mountain, piedmont, and basin units from the AST14DEM image of Islamabad, four object primitive levels of segmentation were found to be necessary. To determine the four effective sets of contextual parameters that produced the fourth and final object primitive level, multiple iterations of manual selection and deletion, prior to establishing the parameters, were required. Only the VNIR image (Fig. 5), composed from the layer stacking of bands (layers) 1, 2, and $3 \mathrm{~N}$ (Table 1), was used as a guide during these iterations. (a)

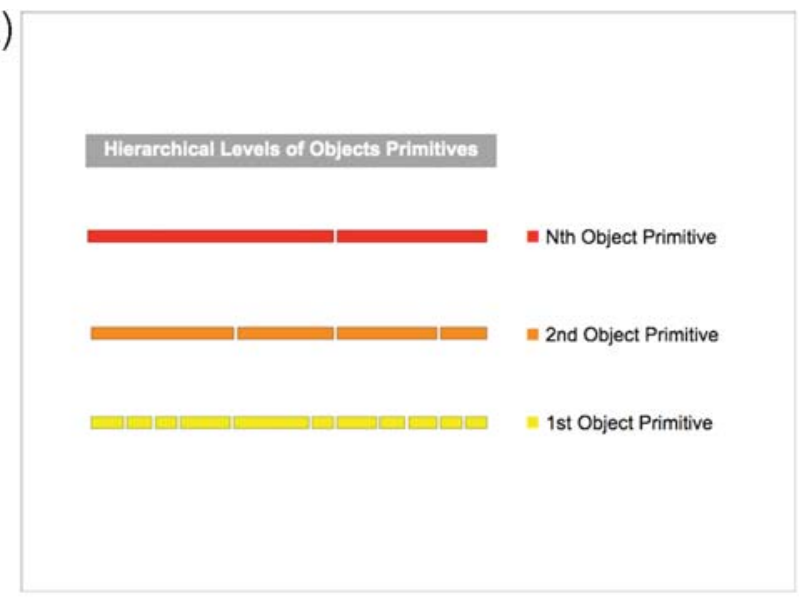

(b)

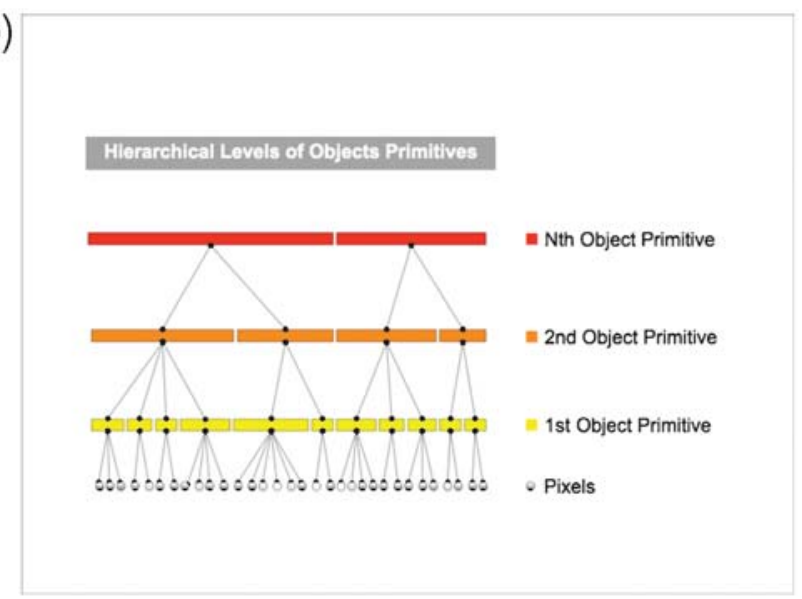

(c)

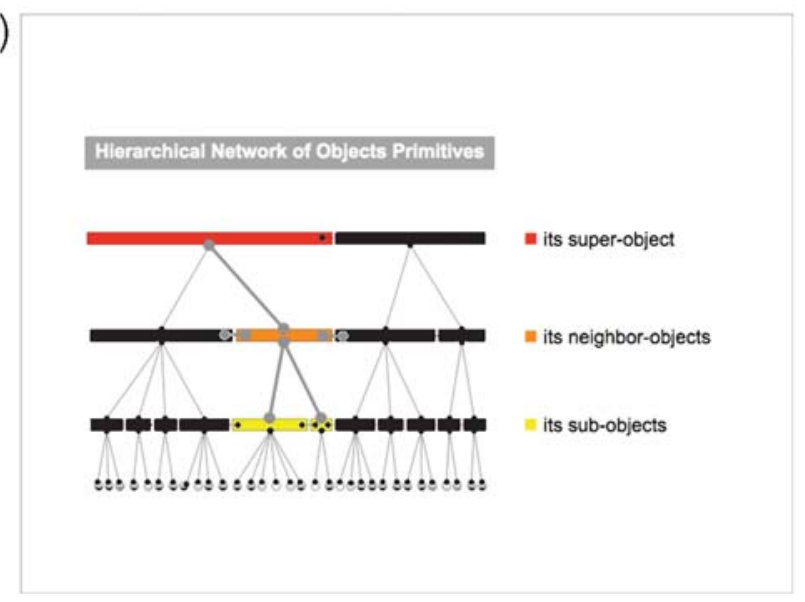

Figure 4. Diagrams (a)-(c) showing the process for the creation of the hierarchical levels of object primitives (Definiens, 2006). Based on the degree of importance assigned to the contextual information, hierarchical levels (a) of object primitives are created. Through the pair-wise clustering of pixels (b), followed by a bottom-up region-merging technique (b), the segmentation process takes advantage of the resultant hierarchical network of object primitives that is cognizant of its neighbor objects (c), its subobjects (c), and its superobjects (c), creating contextual information at multiple scales (Definiens, 2006). 


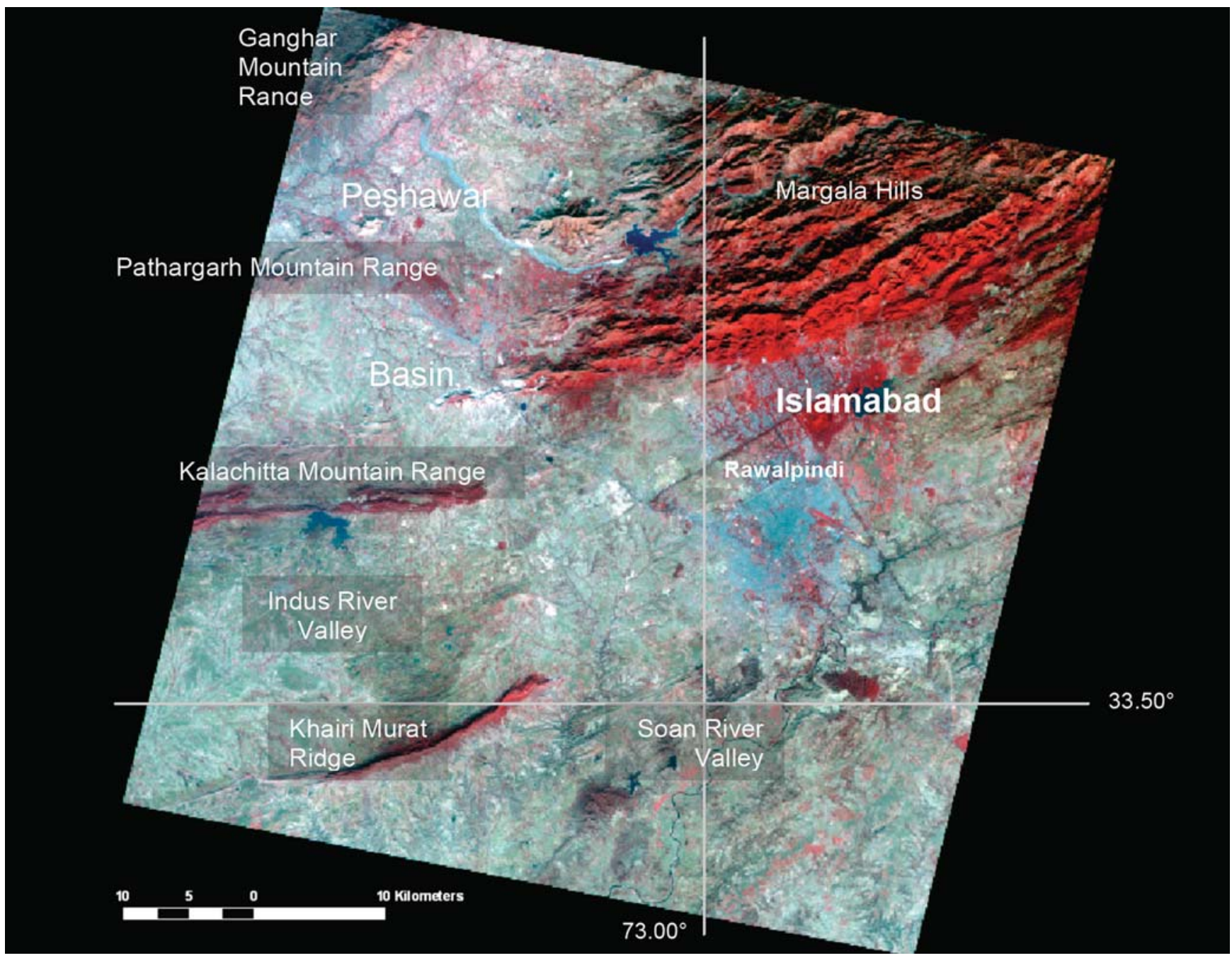

Figure 5. False color ASTER VNIR composite in output space, where layer 3N (0.78-0.86 $\mu \mathrm{m})$, layer $2(0.63-0.69 \mu \mathrm{m})$, and layer 1 $(0.52-0.60 \mu \mathrm{m})$ are assigned to the RGB display channels (respectively). Vegetation is displaying the color red as a result of the lack of spectra collected in the blue wavelength by the ASTER VNIR detector channels.

No other information about the character of the local terrain was used.

The contextual parameters defined for the first object primitive level are given in Table 2. The first object primitive level (Fig. 6a) produces a very dense scene filled with small object primitives that outlined the steep relief terrains (dark areas) in the northwest corner, the upper northeast quadrant, and the southwest quadrant.

The second object primitive level (Fig. 6b) is derived from the first (previous) object primitive level with modified parameters as given in Table 2. The second object primitive level scene maintains the outline of the steep terrains as characterized by the dark features in the first object primitive level. Other steep terrains, previously not apparent, start to take shape (Fig. 6b).

The third object primitive level (Fig. 6c) was based on the second (previous) object primitive level and the modified parameters given in Table 2. This level reveals a more coherent segmentation result, in terms of distinguishable terrain features. The steep relief terrains (dark areas) in the northwest corner, the upper northeast quadrant, and the southwest quadrant implied in the first object primitive level have now taken form (Fig. 6c). A ridge, not previously apparent at the top of the southwest quadrant, has now also taken form.

In the fourth and final object primitive level (Figs. 6d and 7), the object primitives were based on the third (previous) object primitive level; the modified parameters given in Table 2. Here, based on visual comparisons with the VNIR composite, the mountain, piedmont, and basin units, represented by the final object primitives, have now taken what we regard as acceptable form (Fig. 6d and 7).

The systematic classification of the object primitives in the final object primitive level is based solely on the nearest neighbor (NN) classifier in eCognition. Through the use of the nearest neighbor statistics method (Clark and Evans, 1954), the NN classifier fills a class predefined by the user through a supervised training approach that samples the representative values (integers) of the class. Then, based on the 
Table 2

Parameterization of the Four Object Primitive Levels (Yong et al., 2008)

\begin{tabular}{crcccc}
\hline Object Primitive Level & \multicolumn{5}{c}{ Parameterization } \\
& Scale & Shape & Color & Compactness & Smoothness \\
\hline 1 & 10 & 0.1 & 0.9 & 0.5 & 0.5 \\
2 & 50 & 0.5 & 0.5 & 0.5 & 0.5 \\
3 & 100 & 0.7 & 0.3 & 0.5 & 0.5 \\
4 (Final) & 250 & 0.3 & 0.7 & 0.5 & 0.5 \\
\hline
\end{tabular}

sampled representative values and a distance metrics (neighborhood), the pixels or, in this case, object primitives are assigned to the associated class or terrain unit.

As an intermediate product, the terrain units can be assigned shear-wave velocity ranges, assuming that the units have typical velocities for mountains (hard rock), piedmonts (intermediate hard to soft rock), and basins (soft rock). But, to ascertain the impedance of these units for shear-wave velocity assignment, additional information, such as the physical properties (geology) of the units, is required.

\section{Spectral (Pixel-Based) Imaging/Analysis}

After the segmentation and classification of the terrain units, the next step is to verify that the compositions of the terrain units in the classification are as expected for mountain (hard rock), piedmont (moderately soft rock), and basin (soft rock) units. The verification of the expected hardness of the composition for the units is based on identification of the rock type. This is done by matching rock spectral signatures from pixels in the satellite imagery to previously established field and laboratory investigations (Hunt and Salisbury, 1974, 1975, 1976).

There are several methods (Kahle and Rowan, 1980; Crowley et al., 1989; Ninomiya et al., 2005; Rowanet al., 2005) for identifying a rock type remotely based on its spectra. We use a variation of the absolute response method, referred to as the Kahle and Rowan (1980) absolute band composite method, to analyze, identify, and match spectra to known spectra-to-rock relationships.

Kahle and Rowan (1980) verified that spectra identified in laboratory conditions are comparable to spectra sampled in the field and acquired remotely via aircraft, and that these spectra can be employed to map lithologic features (Hunt and Salisbury, 1974, 1975, 1976). After determining that the spectra from each acquisition vantage point matched laboratory spectra with high certainty, Kahle and Rowan (1980) mapped their field area based only on the remotely sensed data. They were able to duplicate the available lithologic map in their study region and in some places to identify other rocks that were previously not described.

Using the ITT-VIS ENVI+IDL, or ENVI (Environment for Visualizing Images) pixel-based imaging analysis software, a combination of the ASTER TIR bands $13(10.25-10.95 \mu \mathrm{m})$, $12(8.925-9.275 \mu \mathrm{m})$, and $10(8.125-8.475 \mu \mathrm{m})$, assigned to display channels R, G, and B, a TIR composite is created (a)

(b)

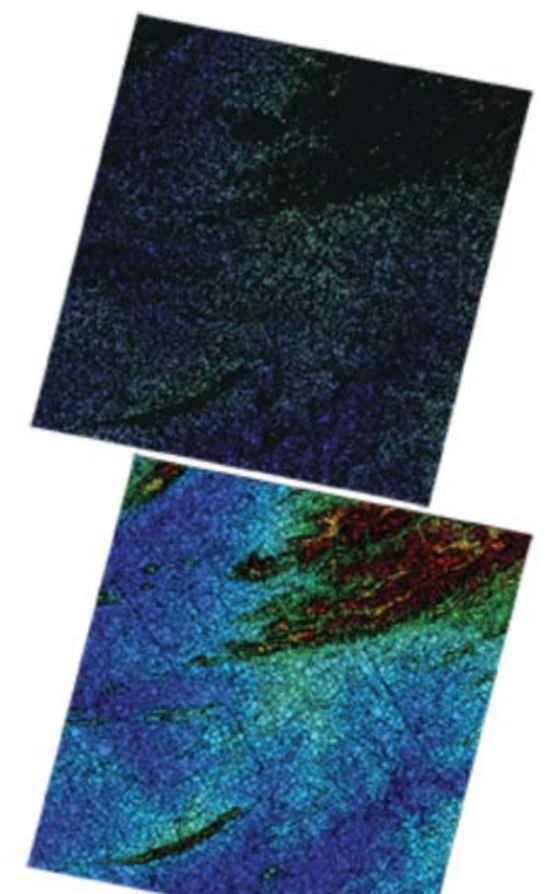

(c)

(d)
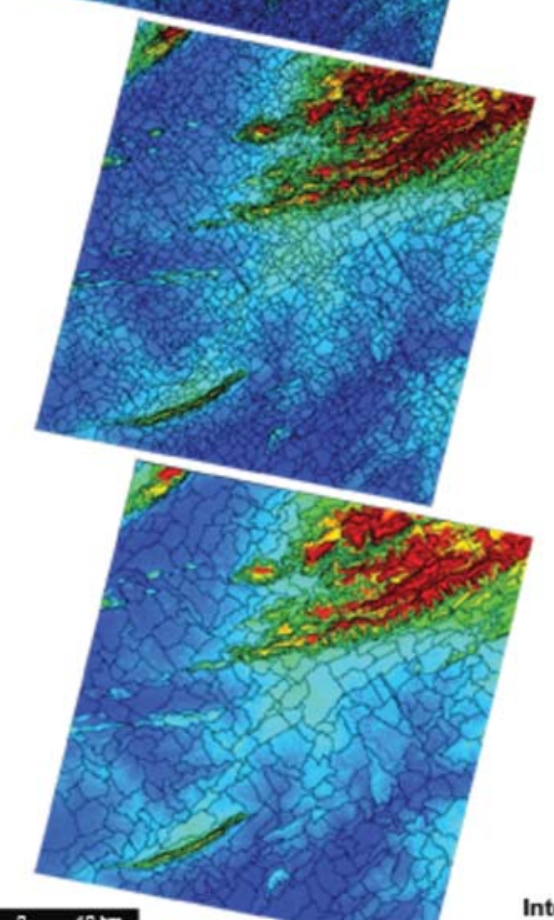

1050

Intensity (relief)

Figure 6. Composites of the four object primitive levels and the relative DEM image (Fig. 3) in sequential order (a)-(d). See Figure 7 for detailed results in Figure 6d.

(Fig. 8a). In this composite, emissivity and temperature control the intensity of brightness, and because materials have distinctive thermal characteristics, these composite images can be used to identify the specific material (Elachi and van Zyl, 2006). A material's temperature is greatly affected by local variations in the surrounding environment, so the material cannot be uniquely identified by temperature alone. Using the ASTER TIR composite as an example, the distri- 


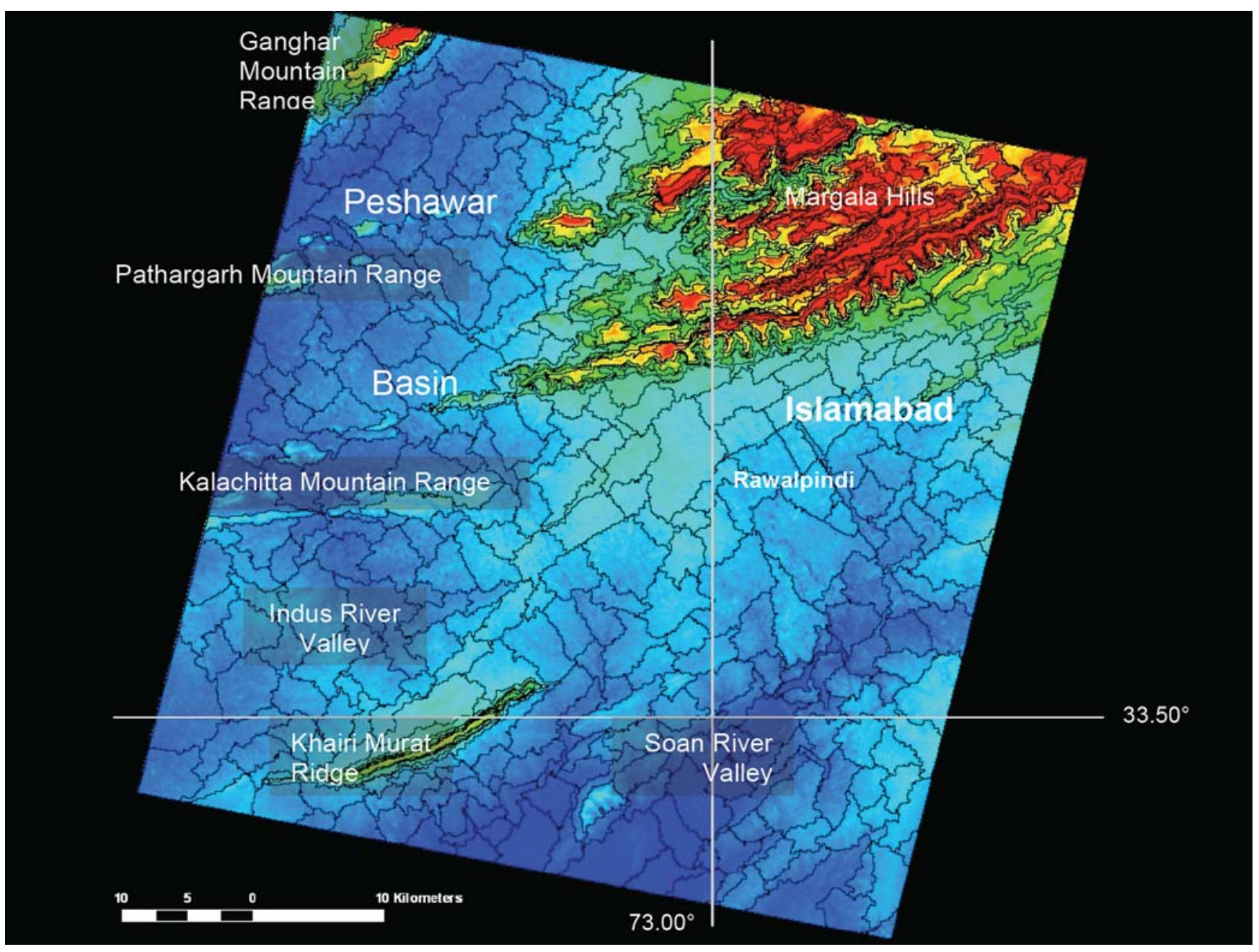

Figure 7. Segmented rDEM-based map (final object primitive level) (Fig. 6d) and physiographic annotations.

bution of the high intensity of brightness in areas of the scene (Fig. 8a) represents the additive effect (band $13+$ band $12+$ band 10 ) of high emissivity in each band region. It is difficult, if not impossible, to visually differentiate between different intensity levels in the TIR composite (Fig. 8a) because the data in each channel are very strongly correlated. To discriminate or enhance the intensity contrast of the pixels in any composite, mathematical transformations (decorrelation functions) can be applied to the data to subdue the visual effect of temperature variations in the scene and exaggerate those that result from emissivity (Adams and Gillespie, 2005).

Our pixel-based analysis employs two types of decorrelation functions to enhance the data. First, an intensity transform, also referred to as an equalization stretch, is applied (Fig. 8b) to the TIR composite (Fig. 8a). Essentially, the equalization method uses a technique that stretches the small intensity contrasts between pixels in the scene to enhance the emissivity information in the image. In the output display (Fig. 8b), the result of the transformation can be interpreted as color describing the decorrelated emissivity information and brightness describing the thermal effects. Next, using a color transform, also referred to as a saturation stretch, another decorrelation function is applied to the TIR composite (Figs. 8c and 9). Essentially, the ENVI saturation stretch uses a technique that transforms or stretches the RGB color space to the HSV color space (Figs. 8c and 9), where the resultant image further enhances the emissivity information through the saturation $(S)$ of the image colors and the reduction of the intensity $(I)$ from the thermal effects.

Our application of the composite of ASTER TIR bands $13(10.25-10.95 \mu \mathrm{m}), 12(8.925-9.275 \mu \mathrm{m})$, and $10(8.125-8.475 \mu \mathrm{m})$, using image postprocessing decorrelation methods, follows Kahle and Rowan (1980), who use the Bendix mid-infrared (MIR) band $17(8.27-8.8 \mu \mathrm{m}), 18$ $(8.8-9.3 \mu \mathrm{m})$, and $20(10.1-11.0 \mu \mathrm{m})$ composite together with image postprocessing enhancements. In addition to sampling the same bandwidths, the RGB assignments to the ASTER TIR and the Bendix MIR bands are the same (Kahle and Rowan, 1980). Kahle and Rowan (1980) found that established laboratory data (Hunt and Salisbury, 1974, 1975, 1976) matched spectra observed during field checks and that the same lab spectra also matched data measured remotely in an airborne investigation over their study area, 
(a)

(b)

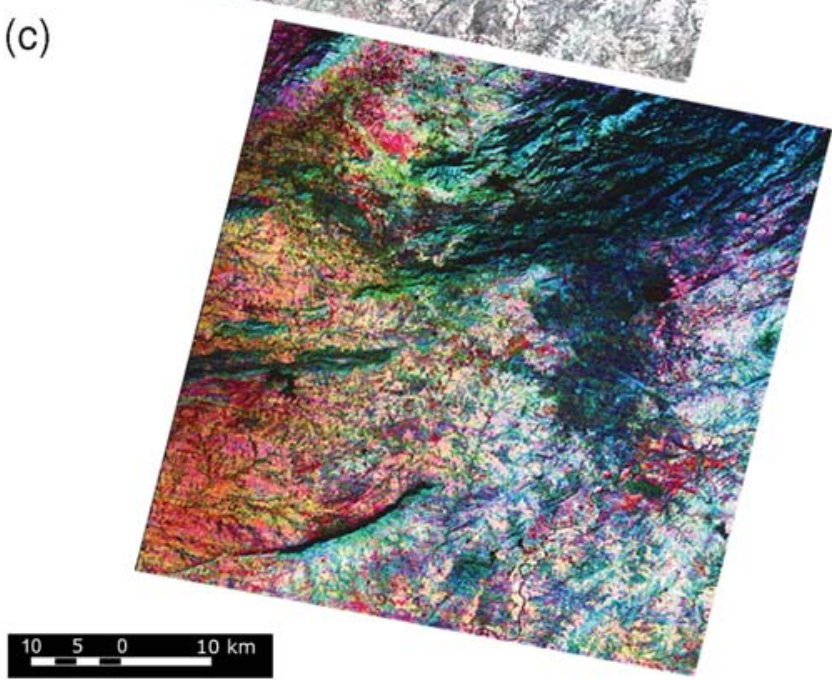

Figure 8. Composites of the ASTER TIR bands 13 (10.25$10.95 \mu \mathrm{m}), 12(8.925-9.275 \mu \mathrm{m})$, and $10(8.125-8.475 \mu \mathrm{m})$, assigned to display channels $\mathrm{R}, \mathrm{G}$, and $\mathrm{B}$, respectively. For the top image (a), no transformation is applied. For the middle (b) and bottom (c) images, equalization and saturation transformations (respectively) were applied. See Figure 9 for detailed results in Figure 8c.

the East Tintic Mountains of Utah. Specifically, Kahle and Rowan (1980) and Kahle et al. (1980) established that the distinct color boundaries in the resultant (decorrelated) composites corresponded to distinct rock-type boundaries. In addition, these studies showed that reds are good indica- tors of silicate content - the more intense and true the red, the higher the silica content; pinks are indicators of silicic areas, sandy limestones, quartz latites, and quartz monzonites; blues indicate latites, monzonites, and some carbonates; purples are clays; and the greens are carbonates, vegetation, and alluvium (Kahle and Rowan, 1980; Kahle et al., 1980). These results thus provide the basis for interpreting color variations in the stretched TIR image (Figs. 8c and 9) in this study.

By applying these methods on the ASTER TIR composite, the uncertainty about the physical properties affecting the impedance of the terrain units can be significantly reduced. For example, we infer the location of the blue and green color-coded regions in the TIR composite (Figs. 8c and 9) to indicate carbonate rocks that coincide with the high relief features in the Margala Hills and the linear ridges. The red and pink color-coded regions indicate silicic deposits in intermediate to low relief terrains that are common materials for piedmonts and basins in the study area.

\section{Assignment of Shear-Wave Velocity Ranges}

For a first approximation, the $V_{s} 30$-lithology correlations of Wills et al. (2000) and Wills and Clahan (2006) can be used for site characterization of expected shear-wave velocities in the near surface. For hard rock sites, Wills and Silva (1998) found the predicted $V_{s} 30$-value to be greater than $500 \mathrm{~m} / \mathrm{sec}$, which is observed mostly in rocks, such as granites, typical of mountain sites in southern California, and as well as in more consolidated sedimentary rocks such as carbonates. Because most mountain features are composed of hard rock and have a characteristically steep topographic profile, the mountain units are assigned the high portion of the velocity range. A large range, $200-600 \mathrm{~m} / \mathrm{sec}$, is assigned to the moderately sloped piedmont units to account for the high variation in velocities that were measured at similar terrains as observed by Wills and Clahan (2006). Lastly, for the soft rock sites, generally correlated to the relatively flat relief of the terrain, the lowest velocity values $(<300 \mathrm{~m} / \mathrm{sec})$ are assigned.

\section{Results and Verification}

Our integrated approach using geomorphic (DEMbased) and geologic (spectral-based) interpretations yields the site classification map as shown (Fig. 10). Our map is a first approximation of site conditions that describe three terrain units (mountain, piedmont, and basin) with inferred shear-wave velocity ranges assigned on the basis of observations from Wills and Silva (1998) and Wills and Clahan (2006). The site classes on this map are derived from satellite data with pixel resolutions at 15 (VNIR bands), 30 (rDEM), and $90 \mathrm{~m}$ (TIR bands), and its equivalent map scale is most accurate at a 1:50, 000 level. A comparison of the classification map (Fig. 10) to the segmented rDEM-based map (Fig. 7) and TIR spectral composite image (Fig. 9) suggests 


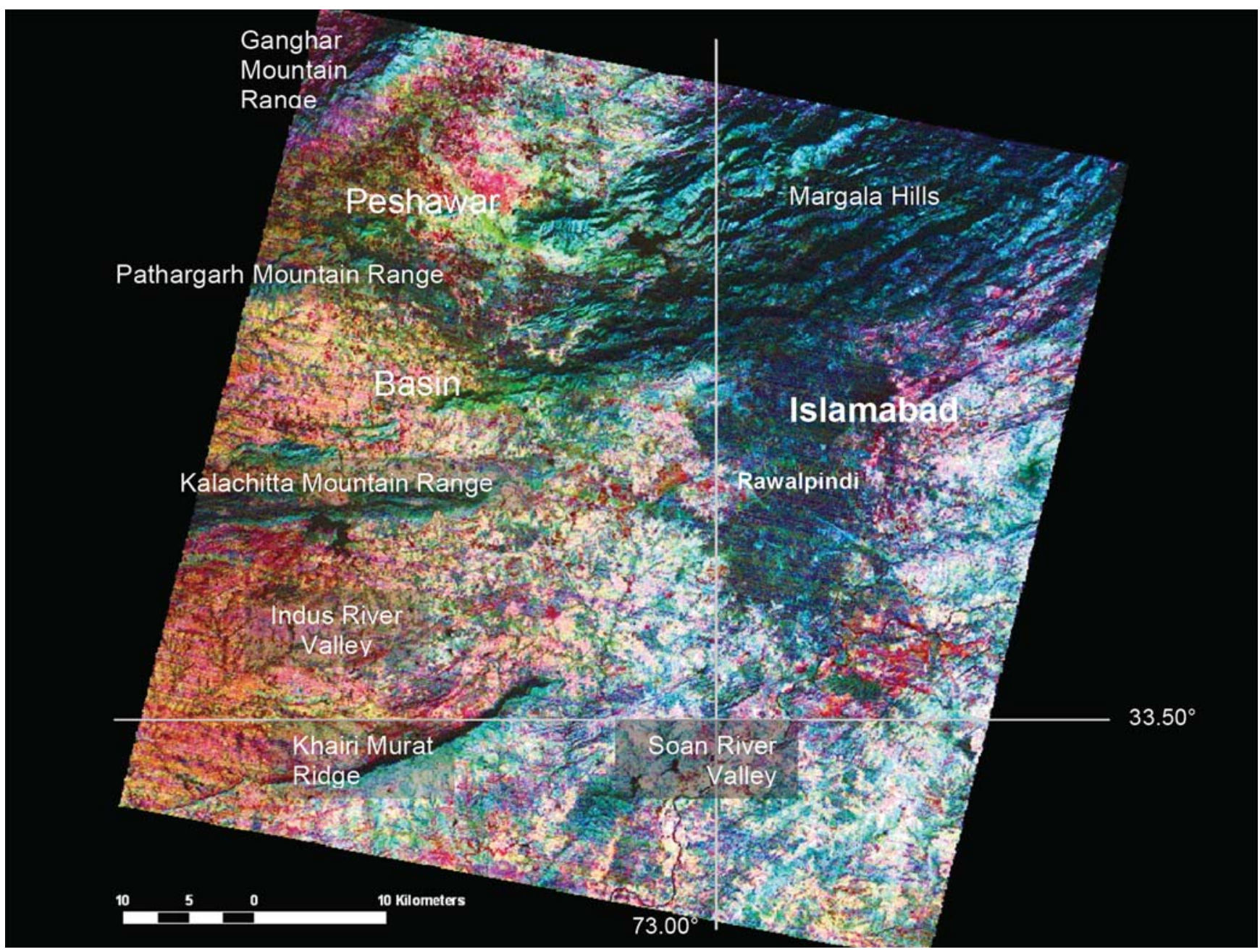

Figure 9. TIR composite map (Fig. 8c) and physiographic annotations.

that the assignments of shear-wave velocity ranges to the terrain units are very well correlated to the expected physical properties of the materials that make up the terrains.

By using only a geomorphometric parameter (slope) and dividing the local landforms into three distinct terrain units (mountain, piedmont, and basin), the first intermediate map (also known as the final object primitive level) (Fig. 7) encapsulates the physiography of our study area. As described in the Digital Analysis Methods section, we apply objectoriented segmentation algorithms (eCognition) on the ASTER rDEM to delineate the geospatial extent of each terrain unit. Known locations of steep and rough terrain features, such as the Margala Hills, the Khairi Murat ridge, and the Kalachitta, the Pathargarh, and the Gandgarh Ranges (e.g., Warwick and Shakoor, 1988; Warwick et al., 1990; Bender and Raza, 1995; Jaswal et al., 1997; Williams et al., 1999) are observed to match our extracted and classified mountain units (Fig. 7). Gradual-sloped and smooth features, occupied by the Peshawar Basin, the Indus River, and the Soan River Valleys, also match their known locations (Warwick and Shakoor, 1988; Warwick et al., 1990; Bender and Raza, 1995; Jaswal et al., 1997; Williams et al., 1999).
The piedmont unit assignments are not as straightforward as the assignments of the other units. For example, the intermediate-sloped piedmont between the Margala Hills and the Soan River Valley is not identified as a piedmont unit by the algorithm. It is possible that the NN classifier approach runs into difficulties in highly urbanized areas where relative topography includes anthropogenic signals. It remains a matter for future research efforts to refine the $\mathrm{NN}$ approach to more effectively handle both anthropogenic signals and intermediate-slope regions. The latter will pose a challenge for any type of automated terrain analysis.

After using geomorphometry on the ASTER rDEM to assign (object-oriented method) the terrain units, we apply pixel-based spectral analysis methods on ASTER VNIR and TIR spectra to reduce the uncertainties about the physical properties (geology) affecting the impedance of the terrain. Mountain areas are shown to primarily consist of limestone and basins to be dominated by silicic (intermediate-soft) rocks (Fig. 9). For verification, rock types derived from the enhanced TIR composite are compared to results of independent investigations. In particular, the locations of the blue and green color-coded regions in the TIR composite (Fig. 9), 


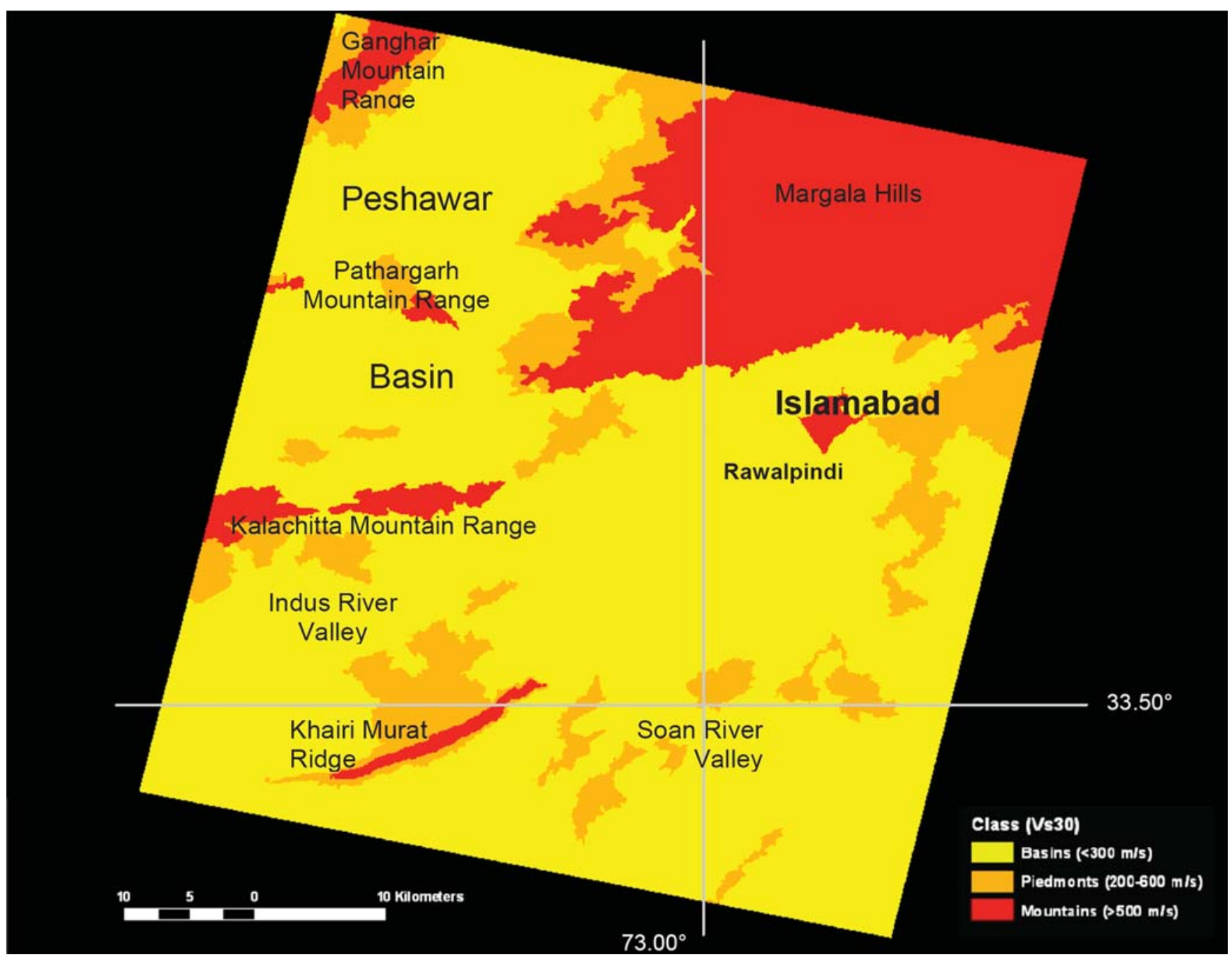

Figure 10. Map of predicted $V_{s} 30$ with verification of compositional rigidity.

which we interpret as high relief carbonate features, match very well with the steep relief and compositional character of lower Eocene limestone mapped in the Margala Hills (Klinger and Richards, 1973; Jaswal et al., 1997; Williams et al., 1999; Nawaz et al., 2004; Munir and Butt, 2007). Furthermore, Nawaz et al. (2004) identified the Margala Hills as the main source of limestone used in the construction of buildings and infrastructure in Islamabad and the surrounding areas. We observe similar TIR signatures in the Islamabad and Rawalpindi metropolitan regions as in the Margala Hills (Fig. 9). Other comparable features matching independent results include the prominent green-coded east-northeast trending Khairi Murat Ridge and the eastern ridge of the Kalachitta Range in the southwest quadrant of the TIR composite (Fig. 9). In separate studies, Warwick et al. (1990) and Jaswal et al. (1997) mapped these linear ridge features and dated them to be of around Paleocene to Eocene age, which closely matches the age (lower Eocene) of the Margala Hills limestone (Williams et al., 1999). Furthermore, Jaswal et al. (1997) assigned both the Khairi Murat Ridge and the Kalachitta Range as rock types predominantly consisting of lime- stone. Based on the intensity of emissivity found in the TIR composite (Fig. 9), we suggest that the Khairi Murat Ridge and Kalachitta Range are very calcareous and are very similar in geology to the Margala Hills limestone. In the low relief basins adjacent to the ridges, red to pink color-coded areas in the TIR composite (Fig. 9) indicate an abundance of siliceous materials (Kahle and Rowan, 1980; Kahle et al., 1980). Because the calcareous sandstone of the Rawalpindi Group include both siliceous and carbonaceous constituents in (effectively) equal amounts (Williams et al., 1999) and the expectation is that these same properties will characterize the detritus on the adjacent basin floors, the dominance of the red to pink color-coded assignments in the basins does not appear to support the conventional understanding of concomitant erosional and depositional processes in arid environments. A possible explanation for the relative abundance of silicates in the adjacent basins is that the silicates are more durable than carbonates and that the relative abundance of silicates in the low areas reflects the durability of the harder siliceous detritus. In addition, the sparse distributions of blue and green color-coded areas, indicating carbonaceous 
materials, found in the adjacent basins, further support our previous explanation about the durability of the detritus. Based on interpretations (Jaswal et al., 1997; Williams et al., 1999) that the Rawalpindi Group (sandstones and claystones) overlies the Cherat Group (limestones and shales), we find our results (surface geology) to complement the results of each study.

Finally, after verifying that the physical properties of each terrain unit are as expected (Wills and Silva, 1998; Wills and Clahan, 2006) for the $V_{s} 30$ ranges, we complete our classification of the velocities onto our site classification map. The Gandgarh Mountain Range, the Margala Hills, the western limbs of the Kalachitta Mountain Range, and the Khairi Murat Ridge are assigned to our highest velocity range $\left(V_{s} 30>500 \mathrm{~m} / \mathrm{sec}\right)$. Intermediate-sloped piedmonts are assigned the large and overlapping intermediate range $\left(V_{s} 30=200-600 \mathrm{~m} / \mathrm{sec}\right)$. The lowest velocities $\left(V_{s} 30<\right.$ $300 \mathrm{~m} / \mathrm{sec}$ ) are assigned to the Peshawar Basin, the Indus River, and the Soan River Valleys. Although we expect established correlations from California to be reasonable for the Islamabad region, direct estimates of $V_{s} 30$ for the lithological units are needed to confirm and possibly refine our preliminary estimates.

\section{Discussion}

The satellite-based ASTER system is the only scientifically accessible system in current operation that includes sensors that record high quality stereo-correlated imagery for generating DEMs on demand (Hirano et al., 2003). ASTER products provide high quality ( \pm 7 to $\pm 15 \mathrm{~m}$ vertical accuracy) DEMs, fine spatial (15-90 m pixel) resolutions, and spectral $(0.52-11.65 \mu \mathrm{m})$ ranges that fulfill the requirements for precise map information (Abrams and Hook, 1995; Hirano et al., 2003; Cuartero et al., 2005). With an equivalent map scale of 1:50, 000 (Hirano et al., 2003), we consider this level of accuracy to be appropriate for microzonation purposes and, by extension, capable of addressing issues of overall damage to a wider area and at a coarser map scale.

There are a few advantages and disadvantages to the approach applied in this study. Our approach has advantages over other approaches used by recent studies (e.g., Romero and Rix, 2001; Wald and Allen, 2007). By using fine spatial $(15-90 \mathrm{~m})$ and multispectral (14 bands) resolution imagery and coupling the geomorphic and geologic properties of landform features, the integrated approach provides improved resolution of the spatial and spectral extent of features that affect site conditions. Also, our technique can be implemented anywhere because ASTER provides complete global coverage. In contrast, a seismic study by Romero and Rix (2001) used satellite imagery with lower spectral resolution (six bands) from the Landsat 7 Enhanced Thematic Mapper Plus (ETM+). The smaller number of channels in the Landsat 7 ETM+ imagery (Kääb et al., 2002), particularly in the TIR, reduces its utility because these regions are crucial for identifying the juxtaposition of complex rock types in seismically active terrains. In a more recent study, Wald and Allen (2007) used DEMs that are at a much coarser spatial resolution (30 arcsec or $900 \mathrm{~m}$ pixel resolution). The DEMs were based on Synthetic Aperture Radar (SAR) technology from the Shuttle Radar Terrain Mission (SRTM). SAR-based DEMs from the SRTM cannot map latitudes north of $60^{\circ}$, which coincides with the seismically active regions of Alaska, and south of $-59^{\circ}$, effectively excluding $1 / 5$ of the Earth's land mass (Pike, 2002). It also cannot accurately map steep areas, which are prominent in most active tectonic terrains.

One disadvantage of the integrated approach is encountered when analyzing large (e.g., continent-scale) regions. The issue is effectively a geometric problem related to the irregular shape of the Earth's surface and the accuracy in the representation of the Earth's curvature over a large region. Although the solution to the problem is not insurmountable, it requires the use of complex and powerful algorithms to accurately produce spatially extensive DEMs. When fine scale spatial accuracy is not required, the Wald and Allen (2007) approach is more practical for characterizing seismic hazards at a continental scale (e.g., Allen and Wald, 2007). Another disadvantage of our approach is that whereas Wald and Allen (2007) can quickly generate a site conditions map by calculating only one parameter (slope) from readily available SRTM DEMs, in the approach described here, both geomorphology and geology, in addition to other preprocesses, are required to prepare the imagery for analysis.

\section{Conclusion}

In our integrated approach, we first use object-oriented image segmentation analysis methods to break up slope (geomorphometry) for assignments to terrain units (mountain, piedmont, and basin) that affect site conditions. Next, we use pixel-based image analysis methods, known as the absolute band composite method (Kahle and Rowan, 1980), to identify the surface composition (geology) of each terrain unit. Then, based on previous observations from Wills and Silva (1998) and Wills and Clahan (2006), we assign $V_{s} 30$ ranges of greater than $500 \mathrm{~m} / \mathrm{sec}$ for mountain units, $200-600 \mathrm{~m} / \mathrm{sec}$ for piedmont units, and less than $300 \mathrm{~m} / \mathrm{sec}$ for basin units.

We find that the combined use of ASTER data and our integrated image analysis approach provides a credible, firstapproximation of potential site amplification in the Islamabad region. At an equivalent map scale of 1:50,000, we find our approach to be appropriate for detailed seismic microzonation, as well as to address issues of overall damage at a regional extent. Because the ASTER data are recorded by a satellite with global coverage, we speculate that our method can be easily applied in other seismically active regions of the world.

Finally, while our map provides a basis for estimating site response in the Islamabad region, any site characterization map needs to be compared and validated with groundmotion recordings. Recorded ground motions from the 2005 
M 7.6 Muzaffarabad earthquake would provide independent estimation of amplification factors. These data have not yet been made available to the international community. In the absence of instrumentally recorded ground motions, a detailed intensity survey of shaking in the Islamabad region during the Muzaffarabad earthquake would also provide a useful basis for comparison.

\section{Data and Resources}

ASTER data used in this study were acquired from the EOS Data Gateway (http://delenn.gsfc.nasa.gov/ imswww/ pub/imswelcome/). Imaging and geospatial analyses were performed using Definiens Professional (version 5.0), ITTVIS (Visual Information Solutions) ENVI + IDL (version 4.3), and ESRI (Environmental Research Systems Institute) ArcInfo (version 9.1) software packages.

\section{Acknowledgments}

We greatly appreciate the helpful review comments by Robert S. Dollar, Karen R. Felzer, and Martin Chapman, in addition to early discussions with Kenneth W. Hudnut and Edward H. Field. We also greatly appreciate technical guidance from David Hulslander and Keith Nicholson of ITT Visual Information Solutions and Matthias Stolz and John Parker of Definiens AG. David Coss Y. Leon contributed to the preparation of the maps for publication. Work done by Michael J. Abrams was performed at the Jet Propulsion Laboratory/California Institute of Technology, under a contract to the National Aeronautics and Space Administration. We thank Linda Gundersen for partial support through the U.S. Geological Survey Working Capital Fund. Partial support was also provided by the California State University, Northridge (CSUN) CATALYST program, funded by National Science Foundation-Geoscience (Number NSF-GEO-0119936 [2001-2005] and Number 0503609 [2005-2009]).

\section{References}

Abrahamson, N. A., and W. J. Silva (1997). Empirical response spectral attenuation relations for shallow crustal earthquakes, Seism. Res. Lett. 68, 94-127.

Abrams, M., and S. J. Hook (1995). Simulated Aster data for geologic studies, IEEE Trans. Geosci. Remote Sens. 33, 692-699.

Abrams, M., S. Hook, and B. Ramachandran (2002). ASTER User Handbook, Jet Propulsion Laboratory/California Institute of Technology, Pasadena, $135 \mathrm{pp}$.

Adams, J. B., and A. R. Gillespie (2005). Remote Sensing of Landscapes with Spectral Images: A Physical Modeling Approach, University Press, Cambridge, 362 pp.

Agarkov, A. V., A. L. Makarov, S. A. Matvienko, and A. V. Meleshko (2005). Geophysical parameters-based space system of Earth remote diagnosis, in the 31st International Symposium on Remote Sensing of Environment, 20-24 June 2005, Saint Petersburg.

Aki, K. (1988). Local site effects on strong ground motion, in Proceedings of the Earthquake Engineering and Soil Dynamics II-Recent Advances in Ground Motion Evaluation, New York, 103-155.

Allen, T. I., and D. J. Wald (2007). Topographic slope as a proxy for seismic site-conditions $\left(V_{s} 30\right)$ and amplification around the globe, U.S. Geol. Surv. Open-File Rept. 1357, 69 pp.

Argialas, D., and A. Tzotsos (2006). Automatic extraction of physiographic features and alluvial fans in Nevada, USA, from digital elevation models and satellite imagery through multiresolution segmentation and object-oriented classification, in American Society for Photogrammetry and Remote Sensing 2006 Annual Conference, 1-5 May 2006, Reno, Nevada.
Baker, D. M., R. J. Lillie, R. S. Yeats, G. D. Johnson, M. Yousuf, and A. S. H. Zamin (1988). Development of the Himalayan frontal thrust zone: Salt Range, Pakistan, Geology 16, 3-7.

Bender, F. K., and H. A. Raza (1995). Geology of Pakistan, Gebruder Borntraeger, Berlin, $414 \mathrm{pp}$.

Bolongaro-Crevenna, A., V. Torres-Rodríguez, V. Sorani, D. Frame, and M. A. Ortiz (2005). Geomorphometric analysis for characterizing landforms in Morelos State, Mexico, Geomorphology 67, 407-422.

Boore, D. M., and W. B. Joyner (1997). Site amplification for generic rock sites, Bull. Seismol. Soc. Am. 87, 327-341.

Borcherdt, R. D. (1970). Effects of local geology on ground motion near San Francisco Bay, Bull. Seismol. Soc. Am. 60, 29-61.

Borcherdt, R. D. (1994). Estimates of site-dependent response spectra for design (methodology and justification), Earthq. Spectra 10, 617-653.

Campbell, K. W. (1997). Empirical near-source attenuation relationships for horizontal and vertical components of peak ground acceleration, peak ground velocity, and pseudo-absolute acceleration response spectra, Seism. Res. Lett. 68, 154-179.

Clark, P. J., and F. C. Evans (1954). Distance to nearest neighbor as a measure of spatial relations in populations, Ecology 35, 445-453.

Coward, M. P., R. W. H. Butler, M. A. Khan, and R. J. Knipe (1987). The tectonic history of Kohistan and its implications for Himalayan structure, J. Geol. Soc. London 144, 377-391.

Crowley, J. K., D. W. Brickley, and L. C. Rowan (1989). Airborne imaging spectrometer data of the Ruby Mountains, Montana: mineral discrimination using relative absorption band-depth images, Remote Sens. Environ. 29, 121-134.

Cuartero, A., A. M. Felicisimo, and F. J. Ariza (2005). Accuracy, reliability, and depuration of SPOT HRV and Terra ASTER digital elevation models, IEEE Trans. Geosci. Remote Sens. 43, 404-407.

Definiens (2006). Definiens Professional 5 Basic Training Material, Definiens AG, Munchen, 69 pp.

Elachi, C., and J. J. van Zyl (2006). Introduction to the Physics and Techniques of Remote Sensing, John Wiley and Sons, Incorporated, New York, $584 \mathrm{pp}$.

Faccioli, E. (1991). Seismic amplification in the presence of geological and topographic irregularities, in Proceedings of the 2nd International Conference on Recent Advances in Geotechnical Earthquake Engineering and Soil Dynamics, St. Louis, Missouri, 1779-1797.

Field, E. H., V. Gupta, N. Gupta, P. Maechling, and T. H. Jordan (2005). Hazard map calculations using grid computing, Seism. Res. Lett. 76, 565-573.

Giardini, D. (1999). The Global Seismic Hazard Assessment Program (GSHAP) 1992/1999, Ann. Geofis. 42, 957-974.

Hirano, A., R. Welch, and H. Lang (2003). Mapping from ASTER stereo image data: DEM validation and accuracy assessment, Photogramm. Remote Sens. 57, 356-370.

Hunt, G. R., and J. W. Salisbury (1974). Mid-infrared spectral behavior of igneous rocks, United States Air Force Cambridge Research Laboratory Technical Report No. AFCRL-TR-74-0625.

Hunt, G. R., and J. W. Salisbury (1975). Mid-infrared spectral behavior of sedimentary rocks, United States Air Force Cambridge Research Laboratory Technical Report No. AFCRL-TR-75-0356.

Hunt, G. R., and J. W. Salisbury (1976). Mid-infrared spectral behavior of metamorphic rocks, United States Air Force Cambridge Research Laboratory Technical Report No. AFCRL-TR-76-0003.

International Conference of Building Officials (1997). Uniform Building Code, International Conference of Building Officials, Whittier, $1411 \mathrm{pp}$.

Jaswal, T. M., R. J. Lillie, and R. D. Lawrence (1997). Structure and evolution of the northern Potwar deformed zone, Pakistan, AAPG Bull. 81, 308-328.

Kääb, A., C. Huggel, F. Paul, R. Wessels, B. Raup, H. Kieffer, and J. Kargel (2002). Glacier monitoring from ASTER imagery: accuracy and applications, in Proceedings of the EARSeL-LISSIG-Workshop Observing Our Cryosphere from Space, 11-13 March 2002, Bern, Switzerland. 
Kahle, A. B., and L. C. Rowan (1980). Evaluation of multispectral middle infrared aircraft images for lithologic mapping in the East Tintic Mountains, Utah, Geology 8, 234-239.

Kahle, A. B., D. P. Madura, and J. M. Soha (1980). Middle infrared multispectral aircraft scanner data: analysis for geologic applications, Appl. Opt. 19, 2279-2290.

Kawase, H. (2003). Site effects on strong ground motions, in International Handbook of Earthquake and Engineering Seismology, W. H. Lee, H. Kanamori, P. C. Jennings and C. Kissinger (Editors), Academic Press, New York, 1013-1030.

Klinger, F. L., and R. L. Richards (1973). Barite in Pakistan, U.S. Geol. Surv. Open-File Rept. 145, 43 pp.

MonaLisa, S. A. Khan, and A. A. Khwaja (2004). Focal mechanism study of north Potwar deformed zone, Pakistan, Acta Seis. Sin. 17, 255-261.

MonaLisa, A. A. Khwaja, and M. Q. Jan (2007). Seismic hazard assessment of the NW Himalayan fold-and-thrust belt, Pakistan, using probabilistic approach, J. Earthq. Eng. 11, 257-301.

Munir, M., and A. A. Butt (2007). The paleogene of Azad Kashmir, Hazara Kashmir syntaxis, Pakistan, in Proceedings of the Geophysical Research Abstracts of the 2007 European Geosciences Union, Volume 9-11052, 15-20 April 2007, Vienna, Austria.

National Earthquake Information Center (NEIC) (2005). News release: magnitude 7.6 Pakistan; Saturday, October 08, 2005 at 03:50:40 UTC, preliminary earthquake report, http://neic.usgs.gov/neis/eq_depot/2005/ eq_051008_dyae/neic_dyae_nr.html (last accessed April 2007).

Nawaz, F., S. Hamidullah, and A. Fayaz (2004). The effect of mining on geomorphology; detection of changes by using remote sensing techniques, in Proceedings of the International Society for Photogrammetry and Remote Sensing 2004 Annual Conference, 19-23 July 2004, Istanbul, Turkey.

Ninomiya, Y., B. Fu, and T. J. Cudahy (2005). Detecting lithology with Advanced Spaceborne Thermal Emission and Reflection Radiometer (ASTER) multispectral thermal infrared "radiance-at-sensor" data, $R e$ mote Sens. Environ. 99, 127-139.

Park, S., and S. Elrick (1998). Predictions of shear-wave velocities in southern California using surface geology, Bull. Seismol. Soc. Am. 88, 677-685.

Pike, R. J. (2002). A bibliography of terrain modeling (geomorphometry), the quantitative representation of topography-supplement 4.0, U.S. Geol. Surv. Open-File Rept. 465, 158 pp.

Pivnik, D. A., and N. A. Wells (1996). The transition from Tethys to the Himalaya as recorded in northwest Pakistan, GSA Bull. 108, $1295-1313$

Reid, H. F. (1910). The mechanics of the earthquake, in The California Earthquake of April 18, 1906, Report of the State Earthquake Investigation Commission, A. C. Lawson (Chairman), Carnegie Institution of Washington, II, 31.

Romero, S. M., and G. J. Rix (2001). Ground motion amplification of soils in the upper Mississippi embayment, Mid-America Earthquake Center at School of Civil and Environmental Engineering at Georgia Institute of Technology Report No. GIT-CEE/GEO-01-1, $461 \mathrm{pp}$.

Rowan, L. C., J. C. Mars, and C. J. Simpson (2005). Lithologic mapping of the Mordor, NT, Australia ultramafic complex by using the Advanced Spaceborne Thermal Emission and Reflection Radiometer (ASTER), Remote Sens. Environ. 99, 105-126.

Sadigh, K., C. Y. Chang, J. A. Egan, F. Makdisi, and R. R. Youngs (1997). Attenuation relationships for shallow crustal earthquakes based on California strong motion data, Seism. Res. Lett. 68, 180-189.

Tinsley, J., S. E. Hough, A. Yong, H. Kanamori, E. Yu, V. Appel, and C. J. Wills (2004). Geotechnical characterization of TriNet sites: a status report, Seism. Res. Lett. 75, 505.

Wald, D. J., and T. I. Allen (2007). Topographic slope as a proxy for seismic site conditions and amplification, Bull. Seismol. Soc. Am. 97, 1379-1395.

Warwick, P. D., and T. Shakoor (1988). Preliminary report on coal characteristics in the Salt Range area of north-central Pakistan, U.S. Geol. Surv. Open-File Rept. 637, 366 pp.
Warwick, P. D., T. Shakoor, S. Javed, S. T. A. Mashhadi, H. Hussain, M. Anwar, and M. I. Ghaznavi (1990). Chemical and physical characteristics of coal and carbonaceous shale samples from the Salt Range coal field, Punjab Province, Pakistan, U.S. Geol. Surv. Open-File Rept. 524, $44 \mathrm{pp}$.

Williams, V. S., M. K. Pasha, and I. M. Sheikh (1999). Geologic map of the Islamabad-Rawalpindi area, Punjab, northern Pakistan (map supplement), U.S. Geol. Surv. Open-File Rept. 47, 16 pp.

Wills, C. J., and K. B. Clahan (2006). Developing a map of geological defined site-condition categories for California, Bull. Seismol. Soc. Am. 96, 1483-1501.

Wills, C. J., and W. Silva (1998). Shear-wave velocity characteristics of geologic units in California, Earthq. Spectra 14, 533-556.

Wills, C. J., M. Petersen, W. A. Bryant, M. Reichle, G. J. Saucedo, S. Tan, G. Taylor, and J. Treiman (2000). A site-conditions map for California based on geology and shear-wave velocity, Bull. Seismol. Soc. Am. 90, S187-S208.

Wood, H. O. (1908). Distribution of apparent intensity in San Francisco, in The California Earthquake of April 18, 1906, Report of the State Earthquake Investigation Commission, A. C. Lawson (Chairman), Carnegie Institution of Washington, I, 220-227.

Yamaguchi, Y., A. B. Kahle, H. Tsu, T. Kawakami, and M. Pniel (1998). Overview of advanced spaceborne thermal emission and reflection radiometer (ASTER), IEEE Trans. Geosci. Remote Sens. 36, 1062-1071.

Yan, G. (2003). Pixel based and object oriented image analysis for coal fire research, M.S. Thesis, International Institute for Geo-information Science and Earth Observation.

Yong, A. (2007). Geophysical site characterization using geomorphology, geology and integrated digital imaging methods on satellite data, M.S. Thesis, California State University, Northridge.

Yong, A., S. E. Hough, M. J. Abrams, and C. J. Wills (2008). Preliminary results for a semi-automated quantification of site effects using geomorphometry and ASTER satellite data for Mozambique, Pakistan and Turkey, J. Earth Syst. Sci. (in press).

Department of the Interior

U.S. Geological Survey

Earthquake Hazards Team

525 South Wilson Avenue

Pasadena, California 91106 (A.Y., S.E.H.)

Jet Propulsion Laboratory

California Institute of Technology

4800 Oak Grove Drive

MS 183-501

Pasadena, California 91109

(M.J.A.)

California State University

18111 Nordhoff Street

Northridge, California 91330

(H.M.C., G.W.S.)

California Geological Survey

$801 \mathrm{~K}$ Street

MS 12-32

Sacramento, California 95814

(C.J.W.)

Manuscript received 6 February 2008 